\title{
CRESCIMENTO INICIAL DE MARCELA (Achyrocline satureioides) EM AMBIENTE PROTEGIDO ${ }^{1}$
}

\author{
INITIAL GROWTH OF MARCELA (Achyrocline satureioides) \\ IN PROTECTED ENVIROMENT
}

\section{Flávia Charão Marques² Ingrid Bergman Inchausti de Barros ${ }^{3}$}

\section{- NOTA -}

RESUMO

Avaliaram-se o estabelecimento e crescimento inicial de plantas de marcela e a viabilidade da produção de mudas a partir de sementes. O estudo foi conduzido em casa de vegetação. A semeadura foi feita a lanço sobre um substrato 1:1:1 de turfa, casca de arroz carbonizada e composto orgânico, em bandejas de alumínio. $O$ delineamento experimental foi completamente casualizado, com 10 repetições. Determinou-se a massa fresca e seca de 10 plantas por repetição a cada 10 dias, até os 70 dias após a semeadura. A germinação das sementes foi desuniforme e o ganho de massa fresca e seca indicou que o crescimento inicial foi lento; havendo maior incremento a partir dos 50 dias da semeadura. $O$ estabelecimento das plantas foi satisfatório e a obtenção de mudas através de sementes foi viável.

Palavras-chave: planta medicinal, propagação, Asteraceae.

\section{SUMMARY}

The stablishment, initial growth and viability of the seedling production by seeds of marcela plants were evaluated. The study was driven at greenhouse. The sowing was made on a pot medium with peat; organic compound and carbonized rice hulls (1:1:1), in trays of aluminum. The experimental design was completely randomized, with 10 replications. Fresh and dry mass was determined every 10 days, until the 70 days after sowing, using 10 plants by replication. Germination was not uniform and plant growth analysis showed that the initial growth was slow, the biggest increment of fresh and dry mass started only at 50 days after sowing. Plant establishment was satisfactory and the seedling production by seeds was viable.

Key words: medicinal plant, propagation, Asteraceae

No Rio Grande do Sul, a marcela (Achyrocline satureioides) é uma planta de grande importância, cuja ação como antiespasmódica, antiinflamatória, antimicrobiana, analgésica e sedativa já foi comprovada pela pesquisa farmacêutica. KNORST (1991) e SENNA (1993) indicam a possibilidade do uso da marcela na indústria farmacêutica e cosmética. Porém, uma questão importante é a disponibilidade de matéria-prima, uma vez que sua obtenção ocorre através do extrativismo.

SCHEFFER (1992) coloca o estudo da propagação de plantas de interesse medicinal como uma das primeiras etapas na pesquisa das espécies com potencial de cultivo. IKUTA (1993) e MARQUES (1995) indicam que a propagação de marcela através de sementes é viável. Assim, o presente trabalho objetivou analisar o estabelecimento e o crescimento inicial das plantas, em ambiente protegido, e indicar a viabilidade da produção de mudas através de sementes.

\footnotetext{
${ }^{1}$ Parte de dissertação apresentada, pela primeira autora, à Faculdade de Agronomia da Universidade Federal do Rio Grande do Sul para obtenção do grau de Mestre em Fitotecnia.

${ }^{2}$ Engenheiro Agrônomo, Mestre em Fitotecnia, Secretaria da Agricultura e Abastecimento do Rio Grande do Sul, Rua Cel. Genuíno, 449/1404, 90010-350, Porto Alegre/RS. E-mail: flaviacharao@ hotmail.com. Autor para correspondência.

${ }^{3}$ Engenheiro Agrônomo, Doutor em Melhoramento de Plantas, Professor Titular da Faculdade de Agronomia/UFRGS. 
O experimento foi conduzido em casa de vegetação do Departamento de Horticultura e Silvicultura da Faculdade de Agronomia/UFRGS, em de Porto Alegre-RS, nos meses de setembro a novembro de 1994. No interior da casa de vegetação, a média das temperaturas mínimas foi de $19,3^{\circ} \mathrm{C}$ e das temperaturas máximas, $28,6^{\circ} \mathrm{C}$. As sementes de $\boldsymbol{A}$. satureioides foram colhidas, em março de 1994, de uma população de ocorrência natural no município de Viamão-RS. A semeadura foi feita superficialmente em bandejas de alumínio $(20 \times 15 \times 5 \mathrm{~cm})$ com 500ml de substrato composto de turfa, casca de arroz carbonizada e composto orgânico na proporção de 1:1:1 (v/v). A maior parte da emergência de plântulas, que teve início entre o terceiro e quarto dia após a semeadura, ocorreu antes de 10 dias, estendendo-se até os 30 dias, quando foi realizado um desbaste, mantendo-se aproximadamente 100 plantas por bandeja. O delineamento experimental foi completamente casualizado com 10 repetições. Foram determinadas a massa fresca $(\mathrm{g})$ e seca $(\mathrm{mg})$ através de amostragens de 10 plantas por repetição a cada 10 dias, até os 70 dias após a semeadura. As plantas foram secas em estufa a $60^{\circ} \mathrm{C}$ até peso constante, com os dados sendo submetidos à análise de variância e de regressão polinomial.

A análise de variância revelou que a regressão quadrática apresentou maior significância estatística. As curvas de regressão mostram que o crescimento inicial ocorreu lentamente (Figura 1). Também, o ganho de massa evidencia que o crescimento inicial foi lento, uma vez que, até os 60 dias após a semeadura, as plantas acumularam 96,4\% da massa fresca e, apenas, 73,3\% da massa seca. Segundo FELIPPE (1986), as novas células formadas nos meristemas desenvolvem-se primeiro por crescimento plasmático, assim, com maior quantidade de tecidos jovens maior o incremento na massa fresca.
O tempo para obtenção de mudas a partir de sementes é superior aos 70 dias, pois ao final do período experimental as mudas não apresentavam condições para o transplantio. Por outro lado, IKUTA (1993) e PARDO (1995) afirmaram que é possível a obtenção de mudas de marcela em 60 e 45 dias utilizando-se estaquia. Entretanto, a obtenção de estacas depende de uma grande disponibilidade de plantas em estado vegetativo, além de exigir mais mão-de-obra e maior área para a produção de mudas. Tendo em vista a implantação de cultivos de marcela, é fundamental que a reprodução através das sementes seja utilizada preferencialmente, garantindo a manutenção da variabilidade genética.

Pelos resultados, pode-se concluir que o crescimento inicial da marcela foi lento, com o estabelecimento das plantas ocorrendo satisfatoriamente, indicando que é possível a produção de mudas a partir de sementes.

\section{REFERÊNCIAS BIBLIOGRÁFICAS}

FELIPPE, G.M. Desenvolvimento. In: FERRI, M.G. Fisiologia vegetal. 2.ed. São Paulo : EPU, 1986. Cap.1, p.1-37.

IKUTA, A.R.Y. Estudos sobre propagação de marcela, Achyrocline satureioides (Lam.) D.C., Compositae. Porto Alegre, 1993. 205 p. Dissertação (Mestrado em Fitotecnia) Curso de Mestrado em Fitotecnia, Universidade Federal do Rio Grande do Sul, 1993.

KNORST, M.T. Desenvolvimento tecnológico de forma farmacêutica plástica contendo extrato de Achyrocline satureioides (Lam.) D.C. Compositae (marcela). Porto Alegre, 1991. 257 p. Dissertação (Mestrado em Tecnologia Farmacêutica) - Curso de Mestrado em Farmácia, Universidade Federal do Rio Grande do Sul, 1991.

MARQUES, F.C. Análise da qualidade de sementes de marcela, Achyrocline satureioides (Lam.) D.C. (Asteraceae), provenientes de duas populações do Rio Grande do Sul. Porto Alegre,1995. 143 p. Dissertação (Mestrado em Fitotecnia) - Curso de Mestrado em Fitotecnia, Universidade Federal do Rio Grande do Sul, 1995.

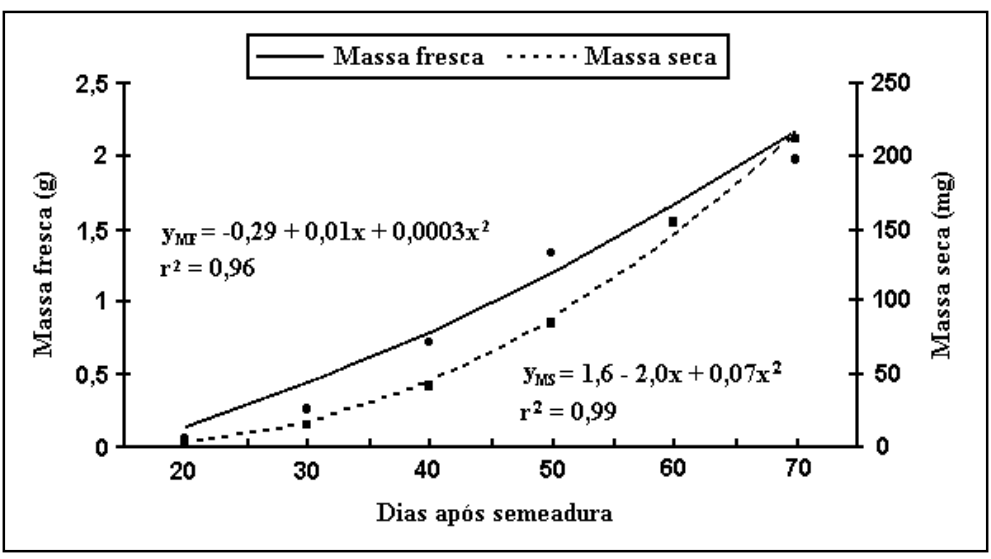

Figura 1 - Massa fresca (g) e seca (mg) de mudas de marcela cultivadas em casa de vegetação até os 70 dias após a semeadura, Porto Alegre, 2000.
PARDO, V.A. Estaquia de marcela Achyrocline satureioides (Lam.) D.C. sob diferentes períodos de enraizmento e doses de ácido indolbutírico. Porto Alegre, 1995. 78p. Dissertação (Mestrado Em Fitotecnia) - Curso de Mestrado em Fitotecnia, Universidade Federal do Rio Grande do Sul, 1995.

SCHEFFER, M.C. Roteiro para estudos de aspectos agronômicos das plantas medicinais selecionadas pela fitorapia do SUSPR/CEMEPAR. SOB Informa, Curitiba, v.10, n.2, p.29-31, 1992.

SENNA, E.M.T.L. Desenvolvimento de extratos secos nebulizados de Achyrocline satureioides (Lam.) DC. Compositae (marcela). Porto Alegre, 1993. 140p. Dissertação (Mestrado em Tecnologia Farmacêutica) - Curso de Mestrado em Farmácia, Universidade federal do Rio Grande do Sul, 1993.

Ciência Rural, v. 31, n. 2, 2001. 